\title{
Surgical tourism and the globalisation of healthcare
}

\author{
C. Healy
}

Received: 26 March 2009/ Accepted: 6 April 2009/Published online: 2 May 2009

(C) Royal Academy of Medicine in Ireland 2009

In an era of globalisation, a growing number of patients are seeking surgical treatment abroad. The term surgical tourism was coined to describe the practice of travelling outside one's principal country of residence for a surgical procedure and the associated burgeoning industry. The estimated worth of this industry was $\$ 60$ billion in 2006 , and is projected to be worth 100 billion in 2012 [1]. The primary driving forces in surgical tourism are the cost of surgical treatment and the length of waiting lists in the principal country of residence, and increasingly the ease with which prospective patients can access information regarding surgical tourism destinations coupled with affordable international travel. However, issues such as lack of regulation and continuity of care continue to raise concerns in the surgical tourism industry.

In America, where 46.6 million residents are uninsured, savings of up to $90 \%$ can be achieved by having surgery performed in a foreign country [2]. Although in Ireland the cost of surgical procedures is far less than that of the US, it is still significantly greater than that of marketed surgical tourism destinations such as India, Thailand and Singapore. Uninsured or underinsured patients are motivated to seek the most keenly priced facility, and the potential savings from travelling abroad ultimately influence their decision.

Waiting lists are a feature of most public healthcare systems and a source of considerable dissatisfaction with patients on those lists. In 2002, to address the Irish public patient in-patient waiting lists, the national treatment purchase fund (NTPF) was introduced. The key goals of the NTPF, as described in the 2007 annual report, are to deliver

C. Healy $(\bowtie)$

Department of Plastic Surgery, Cork University Hospital,

Wilton, Cork, Ireland

e-mail: claraghhealy@rcsi.ie quality of care at the best market prices. In 2007 a revenue budget of 91.744 million, equating to approximately $0.5 \%$ of government health expenditure, facilitated the in-patient treatment of 22,069 patients. Of this number, less than $1 \%$ of the treated patients had their surgeries carried out abroad [3]. The NTPF and similar arrangements in other jurisdictions have a mandate to treat as many patients as quickly as possible within the limits of available funding. As pressure on health expenditure in the current economic climate increases can we expect the percentage of patients sent away to 'cheaper' destinations to increase? Furthermore, cross-border care within the EU is regulated using the basic principles of European and international law. In 1998 the European Court of Justice ruled on two key cases, that of Decker and Kohll, which introduced a new dimension in European health policy making [4]. In the case of Mr. Decker the court ruled that his health insurance providers' refusal to reimburse him for the cost of a pair of spectacles outside his principal country of residence was against the EC treaty freedom of movement of goods [5]. In the case of Mr. Kohll the court upheld the right to obtain and be reimbursed for dental treatment in another EU country without prior authorisation. Therefore healthcare was deemed as tradeable, and available to all EU citizens regardless of their country of residence. Since the European Court of Justice (ECJ) has accepted that healthcare should be considered as a service in terms of the EC treaty, rights to healthcare have become inextricably linked with the free movement principles and are no longer restricted to the jurisdiction of the country of origin. More recently the European Court of Justice ruled in the cases of GeraetsSmits and Peerbooms from the Netherlands and determined that authorisation for treatment abroad that is deemed "normal" by international medical science cannot be refused if medical treatment cannot be obtained without 
undue delay in the resident state [6]. However the term "without undue delay" was not defined, and whether undue delay is a pan-European standard or a matter for individual states would have considerable implications. In Ireland it may be reasonably argued that "undue delay" occurs for most procedures when compared to Belgium, where waiting lists are negligible. The Netherlands has established "Treek norms" to represent acceptable waiting times: all patients should be able to visit an outpatient clinic within 5 weeks and should receive in-patient hospital care within 8 weeks. If these norms were applied to Ireland in conjunction with the rulings of the European Court of Justice it would almost certainly reduce our health service to an emergency and urgent care service only given our fundamental inability to treat elective public patients within any of these European time limits with the government being legally obliged to reimburse any patient electing to be treated in another EU state.

The third major driving force to surgical tourism is accessibility. Thomas Friedman in his book, "The World is Flat" describes a flattening of the global economic playing field, which is driven by individuals who are able to connect, compete and collaborate on-line in a manner unseen before [7]. Healthcare globalisation is evident in established health services. Trunkey, with reference to Thomas Friedman's thesis, reported that "the medical world is flat too" and argues that globalisation of healthcare will improve access and reduce the financial burden to patients [8]. Simply by browsing the Internet prospective surgical tourists can access an unlimited quantity of information pertaining to hospital facilities, medical professionals and supposed patient testimonials, none of which is regulated or verified by recognised advertising or medical standards. Globalisation in healthcare is ubiquitous already with $\mathrm{X}$-rays and CTs being digitised and sent from locations such as the United States and here in Ireland to countries such as Spain and Australia for immediate reporting, with pharmaceutical firms having head offices in developed nations but manufacturing many products in developing countries, with medical professionals themselves undertaking clinical fellowships abroad as a routine element of training and with hospital services in many developed nations, including our own, absolutely dependent on nonnational nurses.

Although proponents point to prompt delivery of cheap and easily accessible medical care, all are not in agreement that surgical tourism represents a panacea. The primary concerns voiced by the medical profession against surgical tourism are potential deficiencies in both continuity and quality of care. A number of recent reports in the transplant and plastic surgery literature examining the outcome and complications of surgical tourism highlight these concerns. Cosmetic tourism has been described as a 'burden' on the
United Kingdom National Health Service due to the requirement for inpatient emergent treatment and corrective or revision surgery $[9,10]$. Comparing a matched cohort of renal transplant patients from University of California, Los Angeles with renal transplant 'tourists', Gill et al. [11] found a more complex post-transplantation course and higher incidence of acute rejection in the tourism cohort. In contrast, Geddes et al. and Canales et al. $[12,13]$ report a generally good outcome for renal transplantation outside of the country of residence. However, in the absence of complete data on the number of patients travelling abroad and the procedures undertaken with all their outcomes it is impossible to accurately assess patient outcome and compare with international standards; the case series and anecdotal reports we have amount at best to level four evidence. In recognition of the perceived lack of regulation in the international medical field, bodies have been established with a remit to regulate international surgical and medical care. One such body is the Joint Commission International, a division of the Joint Commission, the largest accreditor of hospitals in the America. This organisation has examined and accredited more than 100 hospitals internationally including 8 hospitals in Ireland. The Trent Accreditation Scheme, established by managers and practitioners of the former Trent NHS Region is actively involved in accrediting hospitals within the UK and Hong Kong. Eventually it is envisaged that any prospective surgical tourist should be able to inform their decision with the assistance of information and regulatory oversight from these types of organisations.

While reflecting on the function of regulatory bodies as perceived from outside a given country, it becomes apparent that surgical tourism and local efforts to this end can also impact on the healthcare provision in the destination country. Improvements in standards to pass accreditation reviews are certainly a potentially positive development and surgical tourism can inject income into the gross national product of the destination countries. However, there remain potential downsides to this development as funds may be diverted from the provision of care to economically disadvantaged local populations prompting the phrase "medical tourism for the masses, medical missions for the masses". For example, in Thailand it has been demonstrated that the focus on tourism has lead to privatisation of many Thai hospitals where medical expenses are now beyond the financial capacity of the resident population [14].

There are also implications for the health service of the country of origin of the tourist. In Ireland the Health Service Executive (HSE) is responsible for providing health and personal social services. It is the largest organisation in the State, employing over 130,000 people, with a budget of $€ 14.7$ billion. However, increasingly the public hospital 
service is becoming an urgent and trauma care facility, with annual increases in the outsourcing of elective surgical procedures via the NTPF. This trend is clearly seen in orthopaedic surgery, one of the few surgical specialities with stand-alone public elective facilities. This speciality has in recent times experienced closure of the unit in Navan, enforced theatre closures in Cappagh National Orthopaedic Hospital and proposed transfer of elective services from St. Mary's Orthopaedic Hospital in Cork. In addition the government has incentivised private health insurance for the ageing population by introducing a levy on the younger healthier population. These measures, in combination with the emerging trend towards surgical tourism, will certainly adversely impact surgical training as elective procedures are performed either in private institutions or potentially abroad. It is clear that if these trends continue we may end up producing surgeons not fully competent in elective procedures at the end of their training. If these trends in Government policies continue we may have to look at alternative models of training such as including training in the private health care system, similar to the American model.

Surgical tourism, in an increasingly market-driven global healthcare, is set to continue with the demand for increased competitiveness and transparency of costs. Regulation and appropriate accreditation is the key to ensuring quality of care and should be addressed by recognised training and accreditation bodies and surgical specialities. Every effort should be made to avoid deepening the inequities in health service provision in provider countries. We should also consider the impact on our own health service and surgical training.

\section{References}

1. Evans RW (2008) Ethnocentrism is an unacceptable rationale for health care policy: a critique of transplant tourism position statements. Am J Transplant 8:1089-1095. doi:10.1111/j.16006143.2008.02213.x
2. York D (2008) Medical tourism: the trend towards outsourcing medical procedures to foreign countries. J Contin Educ Health Prof 28:99-102. doi:10.1002/chp.165

3. NTPF (2008) NTPF annual report 2007. http://www.ntpf.ie/news/

4. Hermans HEGM (2000) Cross-border health care in the European Union: recent legal implications of "Decker and Kohl". J Eval Clin Pract 6:431-439. doi:10.1046/j.1365-2753.2000.00250.x

5. European Court of Justice (1998) Nicolas Decker v. Caisse de Maladies des Employees Prives, Case 120/95

6. Brouwer W, van Exel J, Hermans B, Stoop A (2003) Should I stay or should I go? Waiting lists and cross-border care in the Netherlands. Health Policy 63:289-298. doi:10.1016/S01688510(02)00120-3

7. Friedman T (2006) The world is flat: a brief history of the twentyfirst century. Farrar, Strausand Girox

8. Trunkey DD (2008) The medical world is flat too. World J Surg 32:1583-1604. doi:10.1007/s00268-008-9522-z

9. Birch J, Caulfield R, Ramakrishnan V (2007) The complications of "cosmetic tourism" - an avoidable burden on the NHS. J Plast Reconstr Aesthet Surg 60:1075-1077. doi:10.1016/j.bjps.2007. 03.030

10. Jeevan R, Armstrong A (2008) Cosmetic tourism and the burden on the NHS. J Plast Reconstr Aesthet Surg 61:1423-1424. doi:10.1016/j.bjps.2008.10.002

11. Gill J, Madhira BR, Gjertson D et al (2008) Transplant tourism in the United States: a single-centre experience. Clin J Am Soc Nephrol 3:1820-1828. doi:10.2215/CJN.02180508

12. Geddes CC, Henderson A, Mackenzie P, Rogder SC (2008) Outcome of patients from the west of Scotland traveling to Pakistan for living donor kidney transplants. Transplantation 86:1143-1145. doi:10.1097/TP.0b013e318187cdd0

13. Canales MT, Kasiske BL, Rosenberg ME (2006) Transplant tourism: outcomes of United States residents who undergo kidney transplantation overseas. Transplantation 82:1658-1661. doi: 10.1097/01.tp.0000250763.52186.df

14. Saniotis A (2007) Changing ethics in medical practice: a Thai perspective. Ind J Med Ethics 3:24-25 